\title{
Gender diversity in developing overweight over 35 years of Westernization in an Inuit hunter cohort and ethno-specific body mass index for evaluation of body-weight abnormalities
}

\author{
Stig Andersen ${ }^{1,2}$, Gert Mulvad ${ }^{3}$, Henning Sloth Pedersen ${ }^{3}$ and Peter Laurberg ${ }^{2}$ \\ ${ }^{1}$ Department of Medicine, Queen Ingrids Hospital, Nuuk, Greenland, ${ }^{2}$ Department of Endocrinology and Medicine, Ålborg Hospital, Århus University \\ Hospital, Denmark, ${ }^{3}$ Primary Health Care Clinic, Nuuk, Greenland
}

(Correspondence should be addressed to S Andersen, Department of Endocrinology and Medicine, Ålborg Hospital, Århus University Hospital, Reberbansgade, DK-9000 Ålborg, Denmark; Email: stiga@dadlnet.dk)

\begin{abstract}
Objective: To establish an Inuit body mass index (BMI) norm from a healthy, not malnourished, pure Inuit population and to investigate the development of overweight in the Inuit in Greenland. Design: Longitudinal study with 35 years follow-up on overweight among Inuit in Greenland. Methods: The heights and weights of 97\% of all inhabitants in Eastgreenland in $1963(n=1852)$ were recovered recently and BMI calculated. We obtained similar data in $96 \%$ of the $50-69$-yearold population in Eastgreenland in 1998 and in a random sample of 25\% of individuals aged $50-69$ years in the capital Nuuk $(n=535)$.

Results: Overweight or obesity, as defined by the World Health Organization (WHO), was found in 30\% of all men and $22 \%$ of all women in Eastgreenland in 1963, and in $31 \%$ of young Inuit hunters in 1963. Such high rates were incompatible with a hunter's way of living. Inuit-specific BMI norms from data on healthy Inuit aged 20-29 years in 1963 were computed: men, 20.2-27.9; women, 17.927.7. These differed from the WHO classification $(P<0.001)$. Using the Inuit-specific BMI norm for the classification of 50-69-year-old Inuit in 1963 and 1998, the fraction of overweight men increased by over six times ( 4.0 to $25.6 \% ; P<0.001$ ), and overweight increased with Westernization $(P=0.001)$. The fraction of overweight women by the Inuit BMI norm doubled from 1963 to 1998 (14.0 to $30.7 \% ; P<0.001)$ while median BMI remained unaltered $(P=0.22)$ because the fraction of slim women more than doubled $(3.5$ to $9.0 \% ; P<0.001)$.

Conclusion: A steep increase in the fraction of overweight Inuit men and women calls for intervention. Westernization predicted increased BMI. In women the increased number of obese people was accompanied by an increased fraction of slim people. This illustrates that transition can be modified and indicates that monitoring of populations in transition should observe gender differences. Finally, the historical data argue against the global applicability of the WHO delineation of normal BMI.
\end{abstract}

European Journal of Endocrinology 151 735-740

\section{Introduction}

Obesity associates with increased morbidity and premature mortality in most populations investigated (1). A number of studies suggest a similar association between morbidity and obesity in Inuit, making obesity an important determinant of disease among circumpolar populations $(2-7)$. Yet, a recent study found that the levels of association between obesity and metabolic risk factors were different in Inuit compared with Caucasians (8). In previous Inuit studies obesity was defined by the World Health Organization (WHO) guidelines (9). These were developed from data on Caucasian populations $(1,9)$ but may not apply to people with different ethnicity.
The prevalence of obesity and overweight has risen sharply worldwide in the past decades $(1,10-12)$ and a similar increase has been reported among Inuit in Alaska and Canada (13-15). In Greenland, the process of modernization accelerated around 1960 (16) with transition from a hunting society to a modern community. It has been suggested that Inuit are genetically prone to develop obesity $(17,18)$ because survival may have been higher among individuals with a high capacity for energy storage, building up of fat deposits $(2,5,8)$. However, a recent cross-sectional study of Greenland Inuit described decreasing overweight among women with Westernization (19). Longitudinal data from Arctic populations may help to clarify such discrepancies, but they are scarce, and lacking for Greenland Inuit $(1,8)$. 
Recently, the original data sheets from an epidemiological study in 1962-1964 of the population in Ammassalik in Eastgreenland were recovered (20, 21). In 1998 we collected similar data in all Inuit in Eastgreenland aged 50-69 years. This allowed for a follow-up study on overweight and obesity in an Inuit cohort which encompasses the first 35 years of Westernization of a pure hunting society. Furthermore, the historic data on young healthy Inuit were used to establish Inuit-specific body mass index (BMI) ranges, and to evaluate the development of supranormal BMI from an ethno-specific BMI norm in addition to the evaluation based on the WHO definition.

\section{Subjects and methods}

Littauer and colleagues conducted epidemiological studies in Greenland in 1962 through 1964. Prevalence of diabetes and charts of height and weight for children have been published previously $(20,21)$ including a description of methods. In brief, they investigated $96.9 \%$ of the whole population in three areas, including Ammassalik in Eastgreenland. All individuals were examined dressed in underclothes and stockings.

The original data charts from the investigation in Ammassalik $(n=1852)$ were donated by the descendents of the late Jørgen Littauer. Charts contained a hand-written report on each individual. They were all intact and readable. Charts included year of birth, gender, a medical history and a physical examination with height in centimeters and weight in kilograms. Two persons were recorded as being dwarfs. Eight women were described as obese and 24 women aged 20 and above were denoted as pregnant.

In 1998 we investigated the population aged 50-69 years living in the main town (Tasiilaq) and the four major settlements (Kuummiut, Kulusuk, Sermiligaaq, and Tiniteqilaaq) in Ammassalik district in Eastgreenland (Fig. 1). Also, a random sample of $25 \%$ of the inhabitants aged 50-69 years in the capital Nuuk in Westgreenland were invited (Table 1). In Nuuk, names and addresses were obtained from the hospital registration system. This had not been regularly updated and for the investigation in Ammassalik names and addresses were obtained from the National Civil Registration System, in which every person living in Denmark, the Faroe Islands and Greenland is registered. This included information on year of birth, gender, and place of living.

We measured height and weight. BMI was calculated as weight in kilograms divided by height in meters squared. Information regarding birthplace of the individual and of parents was obtained by an interview. Classification as Inuit required that the participant and both parents were born in Greenland.

Inuit-specific normal ranges for BMI were established for the 20-29-year-old 1963 population $(n=295)$.

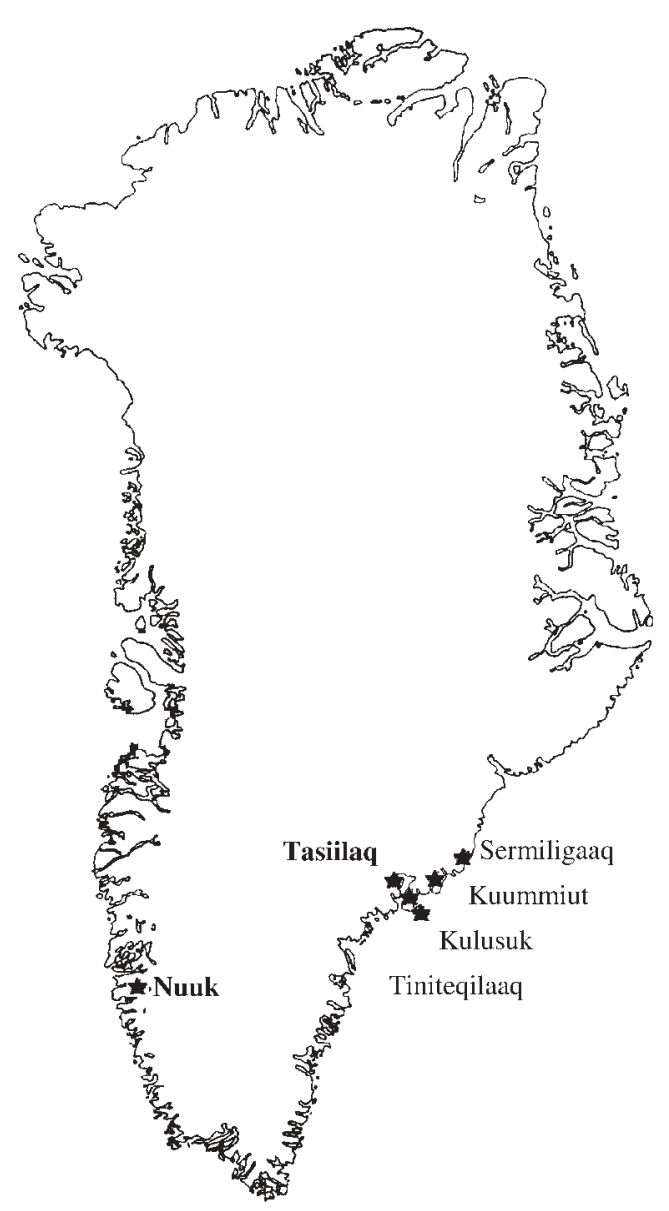

Figure 1 Map of Greenland showing the investigational sites in 1963 and 1998. Nuuk in Westgreenland is the capital of Greenland. Tiniteqilaaq, Sermiligaaq, Kuummiut, and Kulusuk are settlements in the Ammassalik district in Eastgreenland, where Tasiilaq is the main town. The Ammassalik district is the size of France, with a population of 2943 .

The 13 pregnant women in that age group were excluded and no additional body-build abnormalities were described. Thus, the Inuit-specific BMI norm was computed as the $90 \%$ confidence interval of the gender-specific BMI distribution in this group.

Nonparametric tests were used to test for difference between two (Mann-Whitney U test) and more (Kruskal-Wallis test) groups, and to test for association between groups (Kendall's tau). Distributions were tested using Kolmogorov-Smirnov test, and $t$-test was used to compare mean BMI in young Inuit as these followed the normal distribution. Homogeneity of variance was tested using Bartlett's test and fractions of overweight were compared using the chi-square test. A $P$ value of less than 0.05 was considered significant.

Ethical approval by the Commission for Scientific Research in Greenland was obtained prior to the commencement of the 1998 study and all subjects gave informed written consent in Danish or Greenlandic by participant choice. 
Table 1 Participant selection and inclusion in 1998.

\begin{tabular}{|c|c|c|c|c|c|c|c|c|}
\hline & \multicolumn{2}{|c|}{ Population registered } & \multirow[b]{2}{*}{ Cohort selected } & \multirow[b]{2}{*}{ No contact on address } & \multirow[b]{2}{*}{ Invited } & \multirow[b]{2}{*}{ Non-attenders } & \multirow[b]{2}{*}{ Investigated } & \multirow[b]{2}{*}{$\%$} \\
\hline & Total & Aged $50-69$ years & & & & & & \\
\hline Nuuk $^{a}$ & 12909 & 1920 & $480^{b}$ & 255 & 255 & 14 & 211 & $94 \%$ \\
\hline Tasiilaq ${ }^{c}$ & 1724 & 197 & 197 & 13 & 184 & 11 & 173 & $94 \%$ \\
\hline Settlements ${ }^{d}$ & 1093 & 175 & 161 & 9 & 152 & 1 & 151 & $99 \%$ \\
\hline Total & & & 838 & & 561 & & 535 & $95 \%$ \\
\hline
\end{tabular}

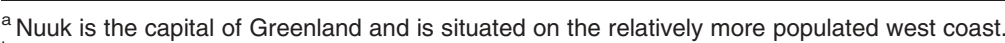

${ }^{b}$ Selected at random.

${ }^{\mathrm{c}}$ Tasiilaq is the main town of Ammassalik county in the sparsely populated Eastgreenland $\left(0.01\right.$ inhabitants $\left./ \mathrm{km}^{2}\right)$.

${ }^{d}$ Only settlements in the Ammassalik district with more than 15 inhabitants in the selected age group were included in the study: Tiniteqilaaq, $n=153$ (total), 19 (aged 50-69 years); Sermiligaaq, $n=174,28$; Kulusuk, $n=366,52$; Kuummiut, $n=400,53$.

\section{Results}

A participation rate of $96.9 \%$ was reported from 1963 (20) and it was $95.4 \%$ in 1998 (Table 1).

\section{Overweight and obesity by the WHO definition}

Overall, $29.1 \%$ of Inuit men and $17.3 \%$ of Inuit women aged 20 and above in 1963 were overweight (BMI 25-30) and $0.6 \%$ men and $4.5 \%$ women were obese $(\mathrm{BMI}>30)$.

Table 2 describes the fractions of slim, normal, overweight and obese Inuit men and women aged 50-69 years in each participant group according to the WHO definition. In $1963,20.0 \%$ of men and $26.3 \%$ of women in that age group had a BMI above 25. In 1998 these figures were 47.5 and $39.2 \%$ respectively.

Among 20-29-year-old healthy Inuit hunters in 1963 , 31\% had a BMI above 25, rendering them overweight by the WHO definition. As discussed below, such high prevalences of supranormal BMI were incompatible with the living conditions of Inuit hunters in Eastgreenland 40 years ago and thus supports the delineation of an ethno-specific optimal BMI for Inuit.

\section{Inuit-specific BMI norm}

The distributions of BMI among men and women aged 20-29 years in 1963 were narrow and symmetrical (Fig. 2). In women, the distribution tended to be positively skewed (kurtosis 0.64), but this was not statistically significant $\left(P_{\text {Normal distribution }}=0.28\right.$ in women;
0.73 in men). Thus, Inuit-specific BMI norms were computed as $90 \%$ confidence intervals for BMI in the healthy 20-29-year-old 1963 Inuit population. BMI differed between genders (mean, $P<0.001$; variance, $P<0.001)$ and the normative values were stratified by gender. Thus calculated, Inuit-specific BMI norms were 20.2-27.9 for men and 17.9-27.7 for women.

\section{Overweight and obesity in 50-69-year-old Inuit in 1963}

By the Inuit-specific BMI norm, $4.0 \%$ of men and $14.0 \%$ of women aged 50-69 years in 1963 were classified as overweight (Fig. 3). If obesity was classified as five BMI units above the upper limit of the 1963 norm, only two women (3.3\%) and no men aged 50-69 years were obese.

\section{Changes in body proportions in 50-69-year- old Inuit over 35 years in transition}

Height in settlements in 1998 was similar to height in 1963 but increased with urbanization (Kendall's tau, $P<0.001$ for both genders; Table 3). So did weight in both men and women $(P<0.001)$ and BMI in men $(P<0.001)$. In contrast, median BMI remained unaltered in women $\left(P_{\text {change }}=0.22\right.$; Table 3, Fig. 3$)$.

Changes in BMI distribution in men and women from 1963 to 1998 are illustrated in Fig. 3. The fraction of overweight, as defined by the Inuit BMI norm, increased from 4.0 to $25.6 \%$ in men $(P<0.001)$ and from 14.0 to $30.7 \%$ in women $(P<0.001)$.

Table 2 Classification of 50-69-year-old participants in weight groups according to the WHO classification.

\begin{tabular}{|c|c|c|c|c|c|c|c|c|c|c|}
\hline & \multicolumn{5}{|c|}{ Men } & \multicolumn{5}{|c|}{ Women } \\
\hline & Slim & Normal & Overweight & Obese & $n$ & Slim & Normal & Overweight & Obese & $n$ \\
\hline $\begin{array}{l}\text { Inuit } 1963^{*} \\
\text { Inuit } 1998\end{array}$ & $2.0 \%$ & $78.0 \%$ & $18.0 \%$ & $2.0 \%$ & 52 & $8.8 \%$ & $64.9 \%$ & $17.5 \%$ & $8.8 \%$ & 60 \\
\hline In settlement & $2.5 \%$ & $58.2 \%$ & $30.4 \%$ & $8.9 \%$ & 79 & $12.7 \%$ & $50.8 \%$ & $12.7 \%$ & $23.8 \%$ & 64 \\
\hline In town & $0.0 \%$ & $50.6 \%$ & $36.7 \%$ & $12.7 \%$ & 80 & $16.9 \%$ & $49.2 \%$ & $11.9 \%$ & $22.0 \%$ & 61 \\
\hline In city & $0.0 \%$ & $43.9 \%$ & $35.0 \%$ & $21.1 \%$ & 70 & $9.0 \%$ & $44.8 \%$ & $22.3 \%$ & $23.9 \%$ & 80 \\
\hline All Inuit & $0.9 \%$ & $51.6 \%$ & $34.0 \%$ & $13.5 \%$ & 229 & $12.7 \%$ & $44.1 \%$ & $15.9 \%$ & $23.3 \%$ & 205 \\
\hline
\end{tabular}

* No difference between Inuit in town and settlement $(P=0.11)$. 

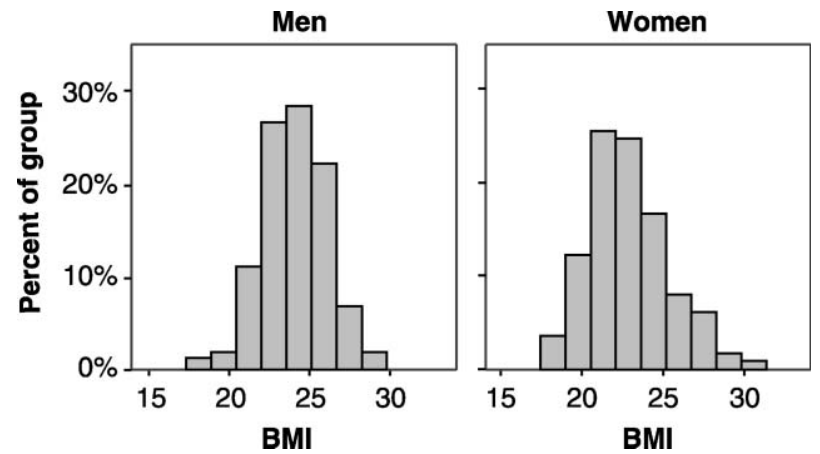

Figure 2 Distribution of BMI among 20-29-year-old Inuit in Eastgreenland in 1963. The cohort included 176 men and 132 women of which 13 were denoted as pregnant. These were excluded from the calculations of normal values. Mean BMI differed between genders $(P<0.001)$, and was 24.0 in men and 22.8 in the 119 non-pregnant women with standard deviations of 2.0 and 2.5 respectively.

The fraction of slim men $(\mathrm{BMI}<20.2)$ was unaltered $(P>0.5)$ but more than doubled in women (BMI $<17.9)$ from 3.5 to $9.0 \%(P<0.001)$. Thus the cohort of men became more obese, while the cohort

Men
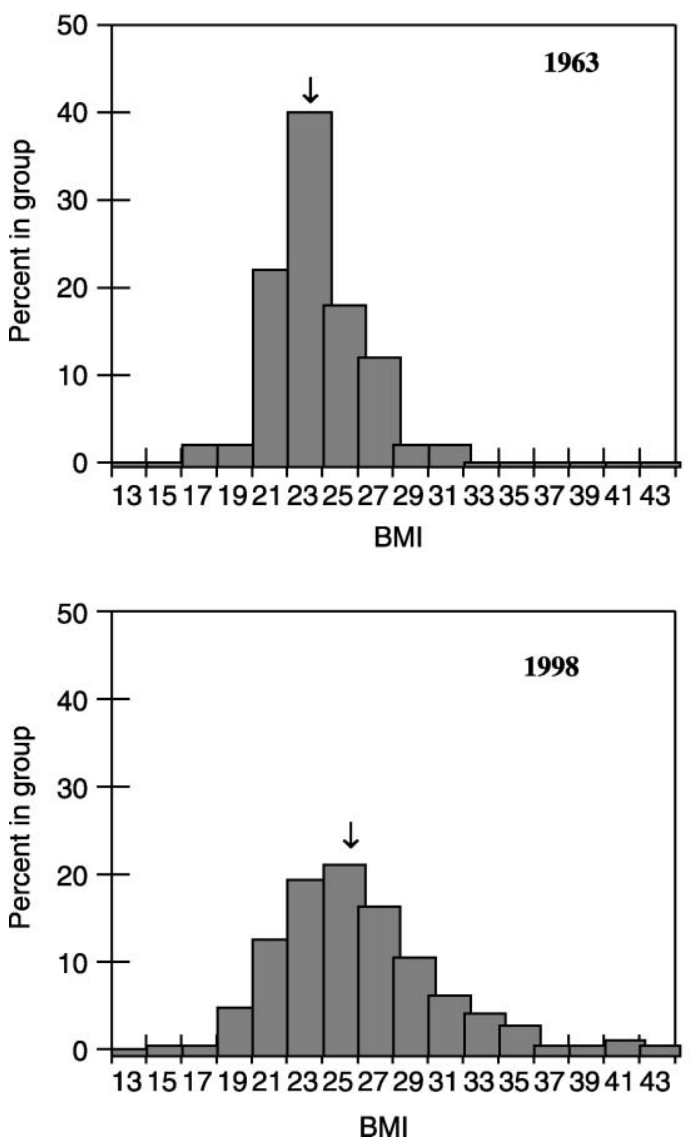

of women became both more obese and more slim (Fig. 3).

The fraction of overweight men increased with urbanization $(P=0.001)$, reaching $33.3 \%$ in Inuit men in the capital Nuuk evaluated by the Inuit norm (Fig. 4) and $56.2 \%$ by the WHO definition (BMI > 25).

\section{Discussion}

Previous estimates of overweight and obesity among Inuit were based on the WHO definition $(8,13-15$, 19) which was developed from data on Caucasians. However, Inuit body build differs from that of Caucasians in that Inuit have larger torsos and shorter limbs $(22,23)$, causing a higher BMI for the same degree of body fat. This is consistent with the finding that the degree of metabolic disturbances is lower at the same BMI in Inuit compared with Caucasians (8). In keeping with this, the WHO definition of overweight and obesity may not apply to Asian populations (24), with whom the Inuit are related (16).

Women
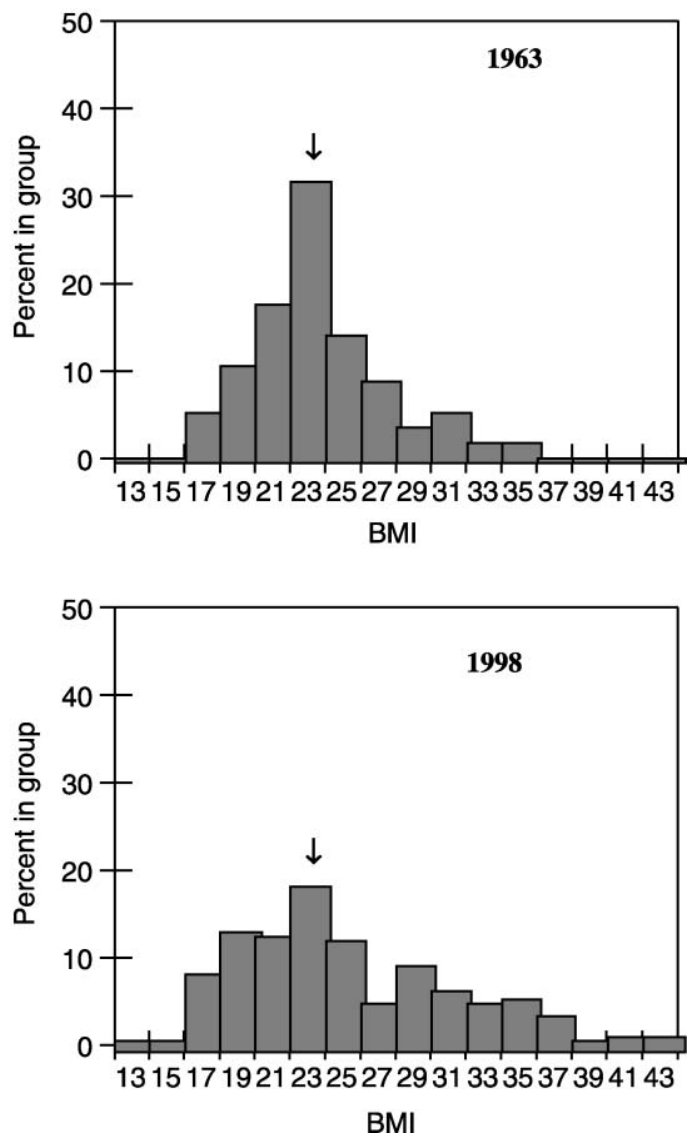

Figure 3 The distribution of BMI in 50-69-year-old Inuit men and women in 1963 and 1998. Arrows indicate median BMI values. The fraction of Inuit with median BMI decreased in both genders over time. In men, more became obese and median BMI increased (both $P<0.001)$. In women, more became obese $(P<0.001)$ but median BMI was unaltered because this coincided with more women becoming $\operatorname{sim}(P<0.001)$. 
Table 3 Height, weight, and BMI among 50-69-year-old Inuit in Eastgreenland in 1963, and Inuit in settlements and towns in Eastgreenland in 1998 and Inuit in city in 1998.

\begin{tabular}{|c|c|c|c|c|c|c|c|c|c|c|c|c|c|c|}
\hline & \multicolumn{7}{|c|}{ Men } & \multicolumn{7}{|c|}{ Women } \\
\hline & \multicolumn{2}{|c|}{ Height } & \multicolumn{2}{|c|}{ Weight } & \multicolumn{2}{|c|}{ BMI } & & \multicolumn{2}{|c|}{ Height } & \multicolumn{2}{|c|}{ Weight } & \multicolumn{3}{|c|}{ BMI } \\
\hline & $\begin{array}{l}\text { Median } \\
\quad(\mathrm{cm})\end{array}$ & $25-75 \%$ & $\begin{array}{l}\text { Median } \\
(\mathrm{kg})\end{array}$ & $25-75 \%$ & $\begin{array}{l}\text { Median } \\
\left(\mathrm{kg} / \mathrm{m}^{2}\right)\end{array}$ & $25-75 \%$ & $n$ & $\begin{array}{l}\text { Median } \\
(\mathrm{cm})\end{array}$ & $25-75 \%$ & $\begin{array}{l}\text { Median } \\
\quad(\mathrm{kg})\end{array}$ & $25-75 \%$ & $\begin{array}{l}\text { Median } \\
\left(\mathrm{kg} / \mathrm{m}^{2}\right)\end{array}$ & $25-75 \%$ & $n$ \\
\hline Inuit 1963 & 161 & $158-165$ & 61 & $58-65$ & 23.4 & $22.0-24.7$ & 53 & 152 & $149-156$ & 53 & $48-61$ & 23.3 & $21.2-25.4$ & 63 \\
\hline Inuit 1998 & & & & & & & & & & & & & & \\
\hline $\begin{array}{l}\text { In settlement } \\
\text { In town }\end{array}$ & $\begin{array}{l}162 \\
166 \dagger\end{array}$ & $\begin{array}{l}158-165 \\
160-170\end{array}$ & $\begin{array}{l}63 \\
68 \ddagger\end{array}$ & $\begin{array}{l}57-70 \\
60-73\end{array}$ & $\begin{array}{l}23.9 \\
24.9^{*}\end{array}$ & $\begin{array}{l}22.2-26.9 \\
22.2-28.4\end{array}$ & $\begin{array}{l}79 \\
80\end{array}$ & $\begin{array}{l}150 \\
157 \dagger\end{array}$ & $\begin{array}{l}148-156 \\
150-160\end{array}$ & $\begin{array}{l}55 \\
56\end{array}$ & $\begin{array}{l}47-69 \\
46-71\end{array}$ & $\begin{array}{l}24.0 \\
22.7\end{array}$ & $\begin{array}{l}20.0-29.3 \\
19.2-29.2\end{array}$ & $\begin{array}{l}64 \\
61\end{array}$ \\
\hline In city & $166 \dagger$ & $160-170$ & 71‡ & $63-79$ & 25.5ł & $23.5-29.1$ & 70 & 155† & $152-159$ & $60 †$ & $54-72$ & 23.9 & $22.0-30.0$ & 80 \\
\hline
\end{tabular}

Mann-Whitney U test, $P: *<0.05, \dagger<0.01, \ddagger<0.001$ compared with Inuit in 1963.

We found that the WHO definition classified many young Inuit in 1963 as overweight. In 1963, Inuit lived a physically very active life depending on hunting and fishing (16). Excessive food intake was limited to short periods after successful hunting followed by periods of food shortage. Also, obesity was a severe drawback when hunting. Thus, obesity was not feasible among male hunters and unlikely among young female Inuit in Eastgreenland in 1963, rendering the obesity rates in 1963 Inuit by the WHO definition unrealistic.

The assessment of the optimal BMI for a population may be done in two ways. One way is to determine the BMI that causes disease. This is probably the most relevant but is a rather cumbersome way. An alternative is to identify a healthy, well-nourished population and estimate an average BMI norm from this population. This could subsequently be related to predisposition to disease.

Access to Greenland was under restrictions by the Danish authorities until around 1960 but trading posts, to avoid periods of famine, and healthcare were

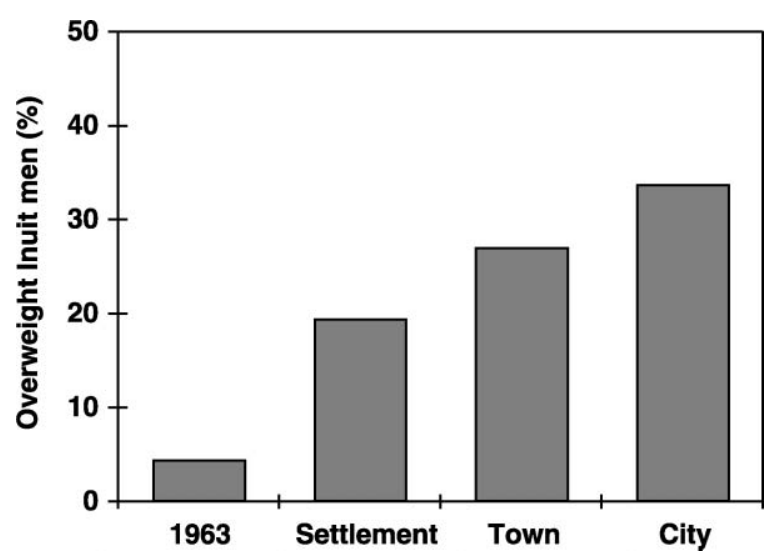

Figure 4 Fraction of overweight Inuit men aged 50-69 years increased with urbanization (Kruskal-Wallis, $P=0.001$; Kendall's tau, $P<0.001$ ). The cohort included 282 Inuit men: 53 in Eastgreenland in 1963; and 79 in settlements, 80 in the main town in Eastgreenland, and 70 in the city of Nuuk in Westgreenland in 1998. Overweight was defined as a BMI above 27.9 which was the upper 90th percentile for BMI in healthy 20-29-year-old Inuit men in 1963. well established in 1963. Hence, the population in Eastgreenland in 1963 was not malnourished. The data from 1963 allowed us to exclude individuals with conditions affecting body build. Thus, the BMI norm for the Inuit population calculated from data on a generally healthy population of young Inuit in 1963 was reliable. Still, our delineation of Inuit-specific normal BMI was mathematical and the limits should be subject to further evaluation.

Westernization has occurred at different paces in different parts of Greenland (16). Today, Inuit in the capital Nuuk have the most Westernized way of living and Inuit in settlements the least, with Inuit in towns being intermediate in their Westernization. These groups were used to analyze the relation between Westernization and overweight and obesity in Greenland Inuit. The historic data allowed for comparison with the original pure Inuit hunting society.

It was not possible to validate data collection in 1963. However, the data collected in 1963 and 1998 were unequivocal with very little risk of inter-observer variability and with no systematic change in calibration. Also, similar and high participation rates in both 1963 and 1998 improve the precision of the estimates made. These factors support the validity of the comparison.

BMI has limitations in evaluation of body fat. It does not distinguish android obesity from the less-dangerous gynoid fat distribution. Also, skinfold thickness and waist/hip ratio and waist circumference may have advantages in describing obesity and risk of disease (1). However, BMI was used for comparison over time and the uncertainty related to the use of BMI was similar in 1963 and 1998. If uncertainty is similar between data collections it evens out in the comparison. Also, pregnant women and Inuit with disabilities affecting height were excluded. Thus, BMI was a reliable parameter for describing development of overweight in Inuit.

The developmental trends were diverse in men and women. In both genders the fraction of Inuit with a normal BMI decreased. Among men, median BMI shifted towards higher values and the prevalence of overweight increased steeply. This associated with Westernization, in keeping with findings in other 
indigenous populations (13, 14, 25). Interestingly, the prevalence of overweight Inuit women increased but the median BMI remained unaltered. This was due to an increased fraction of slim women. This diverse pattern could be part of the explanation for the recent finding of decreasing overweight with Westernization among Greenland Inuit women (19). The gender-specific changes in BMI emphasize the importance of contemplating gender differences when monitoring of indigenous populations in transition.

Overweight in Greenland Inuit associates with increased prevalence of type 2 diabetes (2) as in other populations and there is a need for preventive measures to influence dietary habits, physical activity, and possibly other factors (26) in Westernized Inuit. Our finding of an increased number of slim Inuit women with Westernization, women who have adapted the western idea of beauty (27), illustrates that it is indeed possible to modify the behaviour of Greenland Inuit.

In conclusion, we found a steep increase in overweight and obesity among Inuit in Greenland which calls for attention, and preventive measures are recommended. These measures should be aimed at groups that are at risk such as Westernized Inuit in cities. Our data demonstrate that developmental trends can be modified but that a gender-specific approach may be necessary. The diverse development in BMI indicates that monitoring of indigenous populations in transition should observe gender differences. Finally, the historic data argue against the global applicability of the WHO definition of normal BMI.

\section{Acknowledgement}

Funding was from Greenland Homerule.

\section{References}

1 World Health Organization. Obesity: Preventing and Managing the Global Epidemic, WHO Technical Report Series, no. 894. Geneva: World Health Organization, 2000.

2 Jørgensen ME, Bjerregaard P \& Borch-Johnsen K. Diabetes and impaired glucose tolerance among the Inuit population of Greenland. Diabetes Care 200225 1766-1771.

3 Young TK, Chateau D \& Zhang M. Factor analysis of ethnic variation in the multiple metabolic (insulin resistance) syndrome in three Canadian populations. American Journal of Human Biology $200214649-658$.

4 Naylor JL, Schraer CD, Mayer AM, Lanier AP, Treat CA \& Murphy NJ. Diabetes among Alaska natives: a review. International Journal of Circumpolar Health $200462363-387$.

5 Jørgensen ME, Pedersen MB, Siggaard C, Sørensen TB, Mulvad G, Hansen JC, Skjoldborg H \& Pedersen EB. Twenty-four-hour blood pressure among Greenlanders and Danes: relationship to diet and lifestyle. Scandinavian Journal of Clinical and Laboratory Investigations $200262413-422$.

6 Murphy NJ, Schraer CD, Theile MC, Boyko EJ, Bulkow LR, Doty BJ \& Lanier AP. Hypertension in Alaska Natives: association with overweight, glucose intolerance, diet and mechanized activity. Ethnic Health 19972 267-275.
7 Young TK. Sociocultural and behavioural determinants of obesity among Inuit in the Central Canadian Arctic. Social Science and Medicine 199643 1665-1671.

8 Jørgensen ME, Glümer C, Bjerregaard P, Gyntelberg F, Jørgensen T \& Broch-Johnsen K. Obesity and central fat pattern among Greenland Inuit and a general population of Denmark (Inter99): Relationship to metabolic risk factors. International Journal of Obesity 200327 1507-1515.

9 World Health Organization. Physical Status: the Use and Interpretation of Anthropometry: Report of a WHO Expert Committee, WHO Technical Report Series, no. 854. pp 321-344, Geneva: World Health Organization, 1995.

10 Seidell JC. Prevalence and time trends of obesity in Europe. Journal of Endocrinological Investigations 200225 816-822.

11 Sturm R. Increases in clinically severe obesity in the United States, 1986-2000. Archives of Internal Medicine $2003 \quad 163$ 2146-2148.

12 Katzmarzyk PT. The Canadian obesity epidemic: an historical perspective. Obesity Research 200210 666-674.

13 Risica PM, Schraer C, Ebbesson SOE, Nobmann ED \& Caballero B. Overweight and obesity among Alaskan Eskimos of the Bering Straits region: the Alaska Siberia Project. International Journal of Obesity 200024 939-944.

14 Young TK. Obesity, central fat patterning, and their metabolic correlates among the Inuit of the central Canadian Arctic. Human Biology 199668 245-263.

15 Orr PH, Martin BD, Patterson K \& Moffatt ME. Prevalence of diabetes mellitus and obesity in the Keewatin District of the Canadian Arctic. International Journal of Circumpolar Health 199857 340-347.

16 Bjerregaard P, Young TK. The Circumpolar Inuit: Health of a Population in Transition. Copenhagen: Munksgaard, 1998.

17 Hegele RA, Anderson C, Young TK \& Connelly PW. G-protein beta3 subunit gene splice variant and body fat distribution in Nunavut Inuit. Genome Research $19999972-977$.

18 Hegele RA, Huff MW \& Young TK. Common genomic variation in LMNA modulates indexes of obesity in Inuit. Journal of Clinical Endocrinology and Metabolism 200186 2747-2751.

19 Bjerregaard P, Jørgensen ME, Andersen S, Mulvad G \& Borch-Johnsen K. Decreasing overweight and central fat patterning with Westernization among the Inuit in Greenland and Inuit migrants. International Journal of Obesity 200226 1503-1510.

20 Sagild U, Littauer J, Jespersen CS \& Andersen S. Epidemiological studies in Greenland 1962-1964 I. Diabetes mellitus in Eskimos. Acta Medica Scandinavia 1966179 29-39.

21 Littauer J, Sagild U, Jespersen CS \& Andersen S. Height and weight in Greenlanders. Arctic Medical Research 197614 46-61.

22 Gessain R. La stature des ammassalimiut en 1935 et 19651966. Bulletins et Mémoires de la Société d'Anthropologie de Paris $197413103-107$.

23 Becker-Christensen FG. Growth in Greenland: development of body proportions and menarcheal age in greenlandic children. International Journal of Circumpolar Health $2003 \mathbf{6 2}$ 284-295.

24 Choo V. WHO reassesses appropriate body-mass index for Asian populations. Lancet $2002 \mathbf{3 6 0} 235$.

25 Trowell HC \& Burkitt DP. Western Diseases: their Emergence and Prevention. Cambridge, MA: Harvard University Press, 1981.

26 Gordon-Larsen P, Adair LS \& Popkin BM. The relationship of ethnicity, socioeconomic factors, and overweight in U.S. adolescents. Obesity Research 200311 121-129.

27 Cachelin FM, Rebeck RM, Chung GH \& Pelayo E. Does ethnicity influence body-size preference? A comparison of body image and body size. Obesity Research $200210158-166$.

Received 1 May 2004

Accepted 20 September 2004 